\title{
I am privileged to have been coauthor with Doug
}

\author{
F.Abraham \\ IBM Almaden Research Center, San Jose, CA 95120, USA
}

Received August 7, 2004, in final form April 15, 2005

When I first met Doug, he was already famous. John Barker and Doug had joined the San Jose IBM Research Division in 1969. I had already been with IBM for three years but at the IBM Palo Alto Scientific Center, a small activity created by the Data Processing Division to help establish stronger ties between IBM and U.S. universities. Stanford University was our neighbor, and I started collaborations on nucleation theory. I decided that I would try computer simulation to address certain issues about liquid droplets. It didn't take long for me to discover that the two world's experts on liquids were sitting in San Jose which is 40 miles away. Of course I'm referring to their recent breakthrough with the invention of the BarkerHenderson perturbation theory of the liquid state [1]: Doug joined John Barker in 1966 at CSIRO in Melbourne and the Barker-Henderson Perturbation Theory for the Liquid State was announced at a Faraday Discussion in Exeter in 1967, and its success is well-known history.

I think that it is fair to say that Doug's love was, and probably still is, the mathematical approach to solving a physical problem. My immediate need was to do simulation, so I hooked up with John who was an expert in Monte Carlo simulation. I wanted to be next to these two fellows so I joined the San Jose Research Lab in the early 70's. Actually, Doug soon took a one year sabbatical to the IBM Watson Research Laboratory in New York and, much to my surprise, did some beautiful simulation studies on the structure of glasses. Upon Doug's returning to San Jose, we convinced management that they needed a statistical mechanics group and I was selected as manager by default. Doug and John would have nothing to do with being a manager. However, they made it very clear to me that my major responsibility was to protect them from the "outside interference" of the IBM world, while making sure that they received the proper recognition for their contributions. I believe that I did a fairly good job.

I am privileged to have co-authored one paper with Doug. It was the $1976 \mathrm{HAB}$ (Henderson, Abraham, Barker) solution for a fluid against a wall [2] $]^{1}$. I made a sug-

\footnotetext{
${ }^{1}$ This paper has been reprinted in volume 100 of Molecular Physics in 2002 as one of the most cited paper published in this journal (Eds.)
} 
gestion and, the next day, Doug had the mathematical solution; less than a day's work because of Doug's mathematical skill and physical insights. After the HAB theory of the solid-liquid interface, Doug branched into the general field of electrochemistry and established collaborative friendships throughout the world, most notably in Mexico, Australia, Germany, Puerto Rico, Canada, Poland, Ukraine, Argentina, Hong Kong, and many other places.

One of the early concerns of the IBM management was Doug's presence at the Lab: actually the lack of it. Doug likes to visit interesting centers of science, irrespective of where they may be located in the world, so I had a significant challenge. I simply listed his papers, invitations and honors. Nothing more was questioned. John Barker once told me, "Doug is the only person I know who has been everywhere twice". Doug's lunchtime stories were always very special. I must admit that having lunch with scientists can be rather uninspiring. Doug's stories were the exception and included his early childhood relocations from his birth place, Calgary, to Toronto and Vancouver early in World War II, his schooling where history was his favorite subject and not much else, his near failure of senior high school math that convinced him to change his study habits, and his summer jobs as a seaman and then a miner. Relevant to Doug's life-long professional interests were an early thermodynamics course given by Professor J.B. Warren, where he learned that there was no theory for liquids, and inspiring lectures by Henry Eyring while visiting University of British Columbia during Doug's undergraduate years. This led to Doug getting his PhD at University of Utah under Eyring in significant structure theory. Doug describes this work as forgettable. While at Utah, Doug took a break by performing a mission to South Africa for his church. This is where Doug met his future lovely bride, Rose-Marie leading to three beautiful daughters Barbara, Sharon and Dianne and eight grandchildren.

Doug left IBM in 1992 (at the time, as Doug puts it, when IBM decided to self-destruct), and joined the faculty of the Metropolitan University (Mexico City) in 1993. In 1995 he took a position at Brigham Young University in Provo, Utah where he remains active and involved with visiting scientists, collaborators, and graduate students till the present day. In closing, I am sure that I am expressing the feeling of all Doug's friends around the world when I say: "It is more than a privilege and honor to know and to have worked with Doug Henderson. Through his wit, talent and caring, Doug has made our lives uniquely richer both intellectually and spiritually".

\section{References}

1. Barker J.A., Henderson D., J. Chem. Phys., 1967, 47, 4714.

2. Henderson D., Abraham F., Barker, J. Mol. Phys., 1976, 31, No. 4, 1291-1295; reprinted 2002, 100, No. 1, 129-132. 